\title{
DÜBLIN
}

Technological University Dublin

ARROW@TU Dublin

\section{Understanding the Dynamic Behaviour of Three Echelon Retail Supply Chain Disruptions}

\author{
John Crowe \\ Technological University Dublin, john.crowe@tudublin.ie \\ Mohammed Mesabbah \\ Technological University Dublin \\ Amr Arisha \\ Technological University Dublin, amr.arisha@tudublin.ie
}

Follow this and additional works at: https://arrow.tudublin.ie/buschmarcon

Part of the Business Administration, Management, and Operations Commons, and the Operations Research, Systems Engineering and Industrial Engineering Commons

\section{Recommended Citation}

Crowe, J., Mesabbah, M. \& Arisha, A. (2015) . Understanding the dynamic behavour of three echelon retail supply chain disruptions. Proceedings of the 2015 Winter Simulation Conference, Huntington Beach, California, December 6t - 9th.pp. 1948-1959.

This Conference Paper is brought to you for free and open access by the School of Marketing at ARROW@TU Dublin. It has been accepted for inclusion in Conference papers by an authorized administrator of ARROW@TU Dublin. For more information, please contact arrow.admin@tudublin.ie, aisling.coyne@tudublin.ie, gerard.connolly@tudublin.ie.

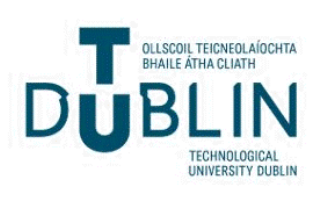




\title{
UNDERSTANDING THE DYNAMIC BEHAVIOUR OF THREE ECHELON RETAIL SUPPLY CHAIN DISRUPTIONS
}

\author{
John Crowe \\ Mohammed Mesabbah \\ Amr Arisha \\ 3S Group, College of Business, \\ Dublin Institute of Technology (DIT) \\ Aungier St, Dublin 2, IRELAND
}

\begin{abstract}
It is often taken for granted that the right products will be available to buy in retail outlets 7 days a week, 52 weeks a year. Challenges in achieving this continued on-shelf availability range from recession hit demand patterns to cost reduction driven strategies. Irish government initiatives to brand the country as a sustainable, reliable provider of food retail supply chains has resulted in increased importance on decision maker accuracy. The vulnerability of retail supply chain's (RSC) to disruption is another catalyst in the complexity of the decision making process and a more robust understanding of disruption behavior is needed. The aim of this paper is to illustrate the advantages of integrating balanced scorecard system thinking to system dynamic modeling of an extended retail supply chain. With this approach, decision makers can gain a better understanding of disruptions within their own organization and the partners within their extended RSC.
\end{abstract}

\section{INTRODUCTION}

The food industry in Ireland is at the core of government strategic plans for growth during such extraordinary economic difficulties over the past 8 years. From "farm to fork" traceability to an Bord Bia's (Irish Food Board) current (2012) initiative, "Pathways for Growth", never has been there a more influential time for Ireland to become a world leader in the supply of sustainable, reliable and safe food products. To achieve this, global confidence and reliability in Irish fast moving consumer goods (FMCG) and grocery retail supply chains (RSC) are essential elements to overall competiveness.

The sectors that make up Irelands RSC network create a very strategic industry in relation to the overall success of the Irish economy. The retail sector alone employs just over $11 \%$ of the total workforce and the entire RSC industry was worth nearly $€ 30$ billion in sales to end consumers in 2013 (Bia 2013). Retail in Ireland is a very competitive market, where the top 5 companies: Musgrave Group Plc., Tesco Plc., Dunnes Stores Ltd, International Spar Centrale BV, and BWG Ltd hold over $40 \%$ share of the market. Apart from the strong competition between the top 5 in becoming market leaders, there are many other barriers to sustaining growth within this market. They include but are not limited to:

- Recession has increased consumer demand for price cuts and promotions.

- Competition from low-cost focused alternatives.

- Sterling strength against Euro increasing competition with Northern Ireland competitors.

- Decreasing demand, $4.5 \%$ decrease 2006-2011, has led to a drive for cost driven strategic plans and increased urgency in operational efficiencies.

- Rising operation costs and pressures to reduce them has increased tension between RSC partners.

- Demand uncertainty and forecast accuracy.

- Food safety standard level consistencies along the entire RSC. 
Crowe, Mesabbah, and Arisha

\subsection{Understanding Retail Supply Chain Challenges}

It is often taken for granted that the right products will be available to buy in retail outlets 7 days a week, 52 weeks a year. A comprehensive understanding of RSC systems is required in order to control rapidly increasing operational costs, greater consumer product knowledge and decreasing brand loyalty, while fulfilling the growing demand for best-in-class pre and post sales service levels and quality products. This means managers within RSC organizations, (such as manufacturers, wholesalers, retailers and logistics providers) have to recognize what are the types of systems and processes that affect decision making; what are the operations within each sub-system; what are the main bottlenecks and their causes; which actions are efficient and which are not; and what is the impact of changes and actions on the overall system performance. According to a survey of RSC stakeholders by the Chartered Institute of Logistics and Transport (CILT) (Fernie and Sparks 2009), there are many challenges confronting RSC's in answering such questions and achieving the ultimate goal of sustainable competiveness. They include; Increasing On-Shelf Availability and Replenishment; Tracking \& RFID; Factory Gate Pricing; MultiChannel Retailing; Global Sourcing and Selling; Localization; Postponement; and Return Management. The supply chain council, a non-profit supply chain research group add that there are 5 key challenges that every supply chain organization face, as shown in Table 1.

Table 1: Supply Chain Challenges (Supply Chain Council, 2013).

\begin{tabular}{|ll|l|}
\hline Challenges & \multicolumn{1}{|c|}{ Description } \\
\hline 1. & Customer Service & $\begin{array}{l}\text { Effective supply chain management is all about delivering the right product in } \\
\text { the right quantity and in the right condition with the right documentation to the } \\
\text { right place at the right time at the right price. }\end{array}$ \\
\hline 2. Cost Control & $\begin{array}{l}\text { Supply chain operating costs are under pressure today from rising freight prices, } \\
\text { more global customers, technology upgrades, rising labor rates, expanding } \\
\text { healthcare costs, new regulatory demands and rising commodity prices. }\end{array}$ \\
\hline 3. $\begin{array}{l}\text { Planning \& Risk } \\
\text { Management }\end{array}$ & $\begin{array}{l}\text { Supply chains must periodically be assessed and redesigned in response to } \\
\text { market changes, including new product launches, global sourcing, new } \\
\text { acquisitions, credit availability, the need to protect intellectual property, and the } \\
\text { ability to maintain asset and shipment security. }\end{array}$ \\
\hline 4. Relationship & $\begin{array}{l}\text { Mifferent organizations, even different departments within the same } \\
\text { organization, can have different methods for measuring and communicating } \\
\text { performance expectations and results. }\end{array}$ \\
\hline 5. Talent & $\begin{array}{l}\text { As experienced supply chain managers retire, and organizations scale up to meet } \\
\text { growing demand in developing markets, talent acquisition, training, and } \\
\text { development is becoming increasingly important. }\end{array}$ \\
\hline
\end{tabular}

To complicate things further, for a RSC that focuses on food FMCG networks, there is the added challenge of short product life-cycles, food safety standards, temperature control, and a very competitive, saturated marketplace. The aim of this paper is to develop a system dynamic based model of the extended RSC of a leading FMCG national distribution center (NDC) in Ireland to aid decision makers in both understanding the consequences of their decisions to the extended RSC and also to highlight the unique behaviors particular disruptions have on the system.

Section 2 will attempt to understand the behaviors involved in the decision making process from a system thinking perspective whilst integrating the advantages of the balanced scorecard (BSC) in both the detection and comparison of performance feedback loops. Section 3 will give a brief profile of the organizations that make up the studied extended 3 echelon RSC and Section 4 gives a detailed account of the modeling methodology and scenarios used to help RSC understand disruptions. Finally, results of chosen scenarios will be presented in Section 5 before the papers conclusions are made in Section 6. 


\section{Crowe, Mesabbah, and Arisha}

\section{UNDERSTANDING DECISION MAKING BEHAVIOR}

A decision needs to be made when an individual or a group faces a choice in which there is more than a single option. The range of possible outcomes may be minuscule, or they might be nearer to infinite and can be further complicated by being multiple or sequential decisions, each of which influence and affect subsequent options (Parnell, Driscoll, and Henderson 2011). Explicit models are useful tools in improving decision making in organizations. These can range from logical to mathematical models. It can be argued that this process in reality is the easy bit for decision makers (Pidd 2009). Pidd highlights that it is much harder to implement, manage and control the continued operation of the consequences of making decisions, and for the majority of organizations, is very time consuming, involving high levels of persuasion, arguments and consultation. This is complicated further by having to "battle" with other changes in the rest of the system that occur during this time and ensuring this does not affect your judgment.

An example of this would be results from a particular analytical model might make it clear to senior management of a retail chain in Ireland that it would be best to restructure their distribution system around one large centralized NDC. The problem is that they currently operate several smaller regional depots. A transition to the single distribution center would take time and many staff are likely to lose their jobs, meaning they are unlikely to cooperate with this transition. The implementation of this strategic decision is probably to be a volatile process, involving many meetings, consultations and arguments. This is not to say that the original model was a waste of time, just that it serves as a basis for control, against which progress can be measured (Pidd 2009). This can be described as a control system, as shown in Figure 1, and are based on the philosophy of feedback. In this system, the mechanism is controlled by the detection (Detector) of its performance, which is then fed back and compared (Comparator) with some target benchmark. This feedback can be conceptualized to represent any decision making process, from the detailed operational level, to more abstract strategic level.

From a whole system perspective, the BSC is uniquely adapted to be able to detect performance and compare metrics covering all key functions within an organization.

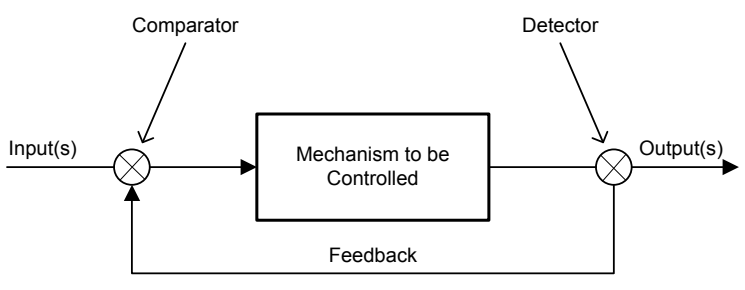

Figure 1: A feedback system (Pidd 2009).

\subsection{Balanced Scorecards (BSC)}

The BSC, pioneered by Kaplan and Norton in 1992, is a systematic methodology that uses strategy-linked leading and lagging performance measures and actions for planning and implementing an organization's strategy (Kaplan and Norton 2001). Among the main benefits of applying the BSC are; 1) an excellent way for communicating and gaining insights into strategic initiatives, key objectives, and actions among decision makers and other staff, 2) a comprehended and easy scheme for compelling the improvement cycles as it facilitates working on analysis, weakness, and potentials for improvements. At its basic level, the BSC provides a framework to look at strategy used for value creation through four perspectives as Kaplan and Norton explain below: 


\section{Crowe, Mesabbah, and Arisha}

1. Financial. The strategy for growth, profitability, and risk views from the perspective of the shareholder.

2. Customer. The strategy for creating the value and differentiation from the perspective of the customer.

3. Internal Business Process. The strategic priorities for various business processes, which create customer and shareholder satisfaction.

4. Learning and Growth. The priorities to create a climate that supports organizational change, innovation, and growth.

With many successful implementations at different organizations, BSC is considered as a popular model and effective means for performance management and strategy execution with SCM (Brewer and Speh 2001, Bhagwat and Sharma 2007, Hult et al. 2008). The BSC perspectives themselves are also closely aligned with the top RSC challenges outlined in Table 1. Although, due to budget constraints, large number of variables, and high levels of uncertainties and dynamics associated with the RSC system, BSC alone will give a limited guide for ensuring planned performance in the chain.

\subsection{System Dynamics Simulation}

System Dynamics (SD) was developed at the end of the 1950s and the beginning of the 1960s at the Massachusetts Institute of Technology's Sloan School of Management by Professor Jay Forrester. He employed the engineering feedback control principles and techniques to management and social science and then applied to any type of complex systems that exhibit dynamic behavior over time. The system dynamics approach seeks to support the decision-making processes that should lead to the improvement of the system, besides it can be very effective in improving the learning in complex systems (Sterman 2000).

Simulation is a powerful tool used to capture the complexity and dynamic features of complex processes including supply chains (Briano et al. 2010, Tobail, Crowe, and Arisha 2011), healthcare (Rashwan et al. 2013) and business processes (Mahfouz, Hassan, and Arisha 2010). Figure 2 shows the strategic road map for developing a SD simulation model for the RSC based on BSC.

\section{SUPPLY CHAIN CASE STUDY}

\subsection{FMCG Brand Supplier}

As a global company, the FMCG Brand Supplier (to be referred to as FMCG) owns some of the world's best-known brands in Personal Care, Home Care, Foods and Refreshment. FMCG has 40 key brands within the Irish FMCG market, of which over 50\% are market leaders. The focus of this paper is on the savory foods category, which includes soups, stocks, meal packs and sauces, a category they are Irish market leader in.

\subsection{Retailer and National Distribution Centre (NDC)}

NDC is a leading grocery retail and wholesale company operating in Ireland and the UK. The company sources products from more than 550 suppliers and service more than 14,000 retail franchise customers, selling over 6,000 products. This paper will focus on one product category, "savory foods". Through its branded retail estate, it serves in excess of one million end consumers every day. The company operates three main retail divisions in Ireland; Foods Retail Division, Foods Wholesale Division, and Wines \& Spirits. Recently, the company has amalgamated its regional distribution centers' into one main national hub for ambient products, with a capacity of 22,500 pallets. Strategically located near Dublin, the new NDC's aim is to meet the volatile demand requirements of customers nationally. Meeting orders, due dates and NDC costs represent priorities for NDC to retain customers and sustain profits in a very competitive market place. The FMCG Brand Supplier modeled is the biggest supplier of savory brands to this retail chain. 


\section{Crowe, Mesabbah, and Arisha}

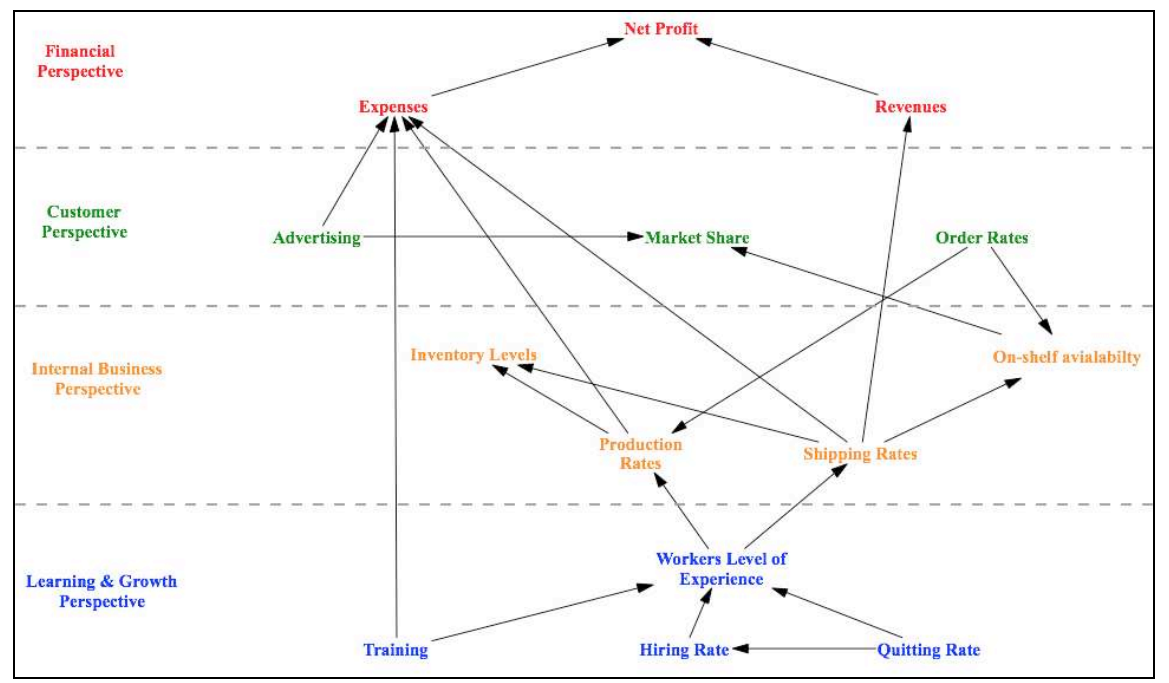

Figure 2: Retail Supply Chain Strategic BSC Roadmap

\section{THE SYSTEM DYNAMICS MODEL}

The system dynamics model is used to model the extended RSC with particular focus on the selected product category of savory brands. The model follows the road map in Figure 2 to feedback causal relations between the variables within the four perspectives of the BSC for both FMCG and NDC. Ultimately, the purpose is to provide decision makers across the extended RSC with a comprehensive model that can be used to understand the unique behaviors, particularly effect of disruptions on the supply chain performance. Accordingly, a set of scenarios are presented as described in Section 4.1 in order to achieve that goal. There is an emphasis on particular sub-modules in the model which is related to the scenarios agreed with the company. Causal loop diagrams for the main variables within these submodules are shown in Figure 3.

The flow of products through the RSC from FMCG (upstream) to the shelves of NDC retailers (downstream) is illustrated (Figure 3-a). The market share is the main driver of the feedback loops that control the retailers behavior. The products availability on-shelves of the retailers positively affect this market share, and consequently the overall consumption of the products leads to reducing product availability on-shelves (loop B1). The change in consumption has a delayed effect on the perceived market demand for the retailers, based on that, they adjust their ordering decisions from the NDC. These decisions affect the overall orders backlog of the NDC and, consequently, the shipping of the products from the NDC to the retailers which, at the end, affect both on-shelf availability and market share (loop R1). Loops B2, B3, B5, B6, B7 and B8 demonstrate how the internal system at the three echelons of the underlying RSC are seeking a balanced state (equilibrium) where they will be able to regulate their orders' rates in order to fulfill customers demand taking into consideration the upstream delivery lead time (e.g. production lead time for FMCG). On the same direction, loop B4 demonstrates the embedded effort of the overall chain towards a balanced state as well. Hence, this RSC is expected to seek a steady state under disruptions. It will lose the current steady state for a certain time period but the internal dynamics of its components interactions will work on either returning to that state or finding a new one.

The key decision at each echelon in the underlying RSC is the daily number of cases (order size) to be ordered subject to two factors. The first factor is the "demand forecast" (expected demand): in this model it is assumed that retailers adjust their expected demand based on the last two weeks consumption while both NDC and FMCG do that based on last month demand from their downstream partners. These forecasting mechanisms create delayed effects of any sudden changes (disruptions) in consumers behavior on retailers, NDC and FMCG decisions. The second factor is the "delivery lead time": within this RSC there are three lead times: 1) production lead time for FMCG; 2) delivery lead time from FMCG to NDC; 


\section{Crowe, Mesabbah, and Arisha}

and 3) the lead time from NDC to retailers. In this model, these lead times are affected by the experience level of workers within FMCG for the first two lead times and the experience level of the workers in NDC for the third one. Causal loops that are responsible for the changes in the overall experience level within FMCG and NDC are shown in Figures 3.b and 3.c. Similar to "demand forecast", there is a delay to perceive the changes in the lead time from one echelon to its downstream customers. As a result of this delay, along with the aforementioned delay of expected demand, there will be a delayed response of decision makers at all echelons to adjust their daily order sizes to upstream suppliers. That will create additional delayed effects back and forth on the other variables in the system (e.g. inventory levels).

\subsection{Disruption Scenarios}

Based on interviews with NDC and FMCG decision makers, an agreed set of scenarios of disruptions in RSC are developed to examine the dynamical behavior of the extended RSC. The model is initialized in order to be in a steady state with constant consumer demand since the purpose of the study is finding out the impact on the overall stability of the supply chain network (Gonçalves, Hines, and Sterman 2005). In the steady state, the consumer demand is constant and therefore the flow of products from the production phase at FMCG down to the retailers are relatively steady. Steady state in this context means business as usual scenario (BAU). A brief description of the disruption scenarios is given below.

\subsubsection{Promotions}

Although FMCG's market share of the savory category in Ireland is very stable at 50\%, there are constant efforts made to increase growth in the market. Primary strategic growth initiatives historically centered on brand market investment (BMI) which focuses on advertisement channels and promotions. These are typically; Buy one get one Free (BOGOF); \% off marked price or \% free incentives; Online competitions and prizes; and Media campaigns and PR events.

Apart from the promotion costs itself, advertising costs also increase during the discount period to increase potential demand for the products. After the increase in demand for the category during a promotion, there is at least a $20 \%$ reduction in demand for $2-4$ weeks due to customers having full cupboards of the product at home to use. This pattern is also evident with the wholesaler as they also are fully stocked because of the promotional discount that was available. Also notable, is that the NDC are 15 - 16\% of FMCG Retail Customer base and their savory category products represents $90 \%$ of NDC retailers sales of the overall savory category. In the model, this scenario assumes that after one month from the steady state the promotion becomes active and the daily consumption raises by $50 \%$ for two months (the promotion period) and after that the consumption will drop by $20 \%$ of its original pattern for one month before it returns to that pattern. S1 is used to that scenario in this work, this scenario will be used as well in the next scenarios in conjunction with the other chosen disruptions.

\subsubsection{Production Disruption}

The main reasoning behind this scenario disruption is that Ireland as a market has only a 1\% market share of total FMCG Europe sales turnover. It is a common occurrence that either Ireland's production capacity is reduced or supply lead times extended due to larger countries such as the UK, France and Germany getting scheduling priority. Ireland's production runs are normally placed at the end of these larger throughputs. The other reason for this disruption is that producing using the full capacity may lead to a drop in this capacity (e.g. maintenance problems) that will cause a decrease in production. So that, in the model to simulate such a scenario, it is assumed that after six weeks from the promotion will begin, the production capacity will drop by $25 \%$ and the production lead time will raise by $50 \%$. The reference to this scenario will be (S2). 


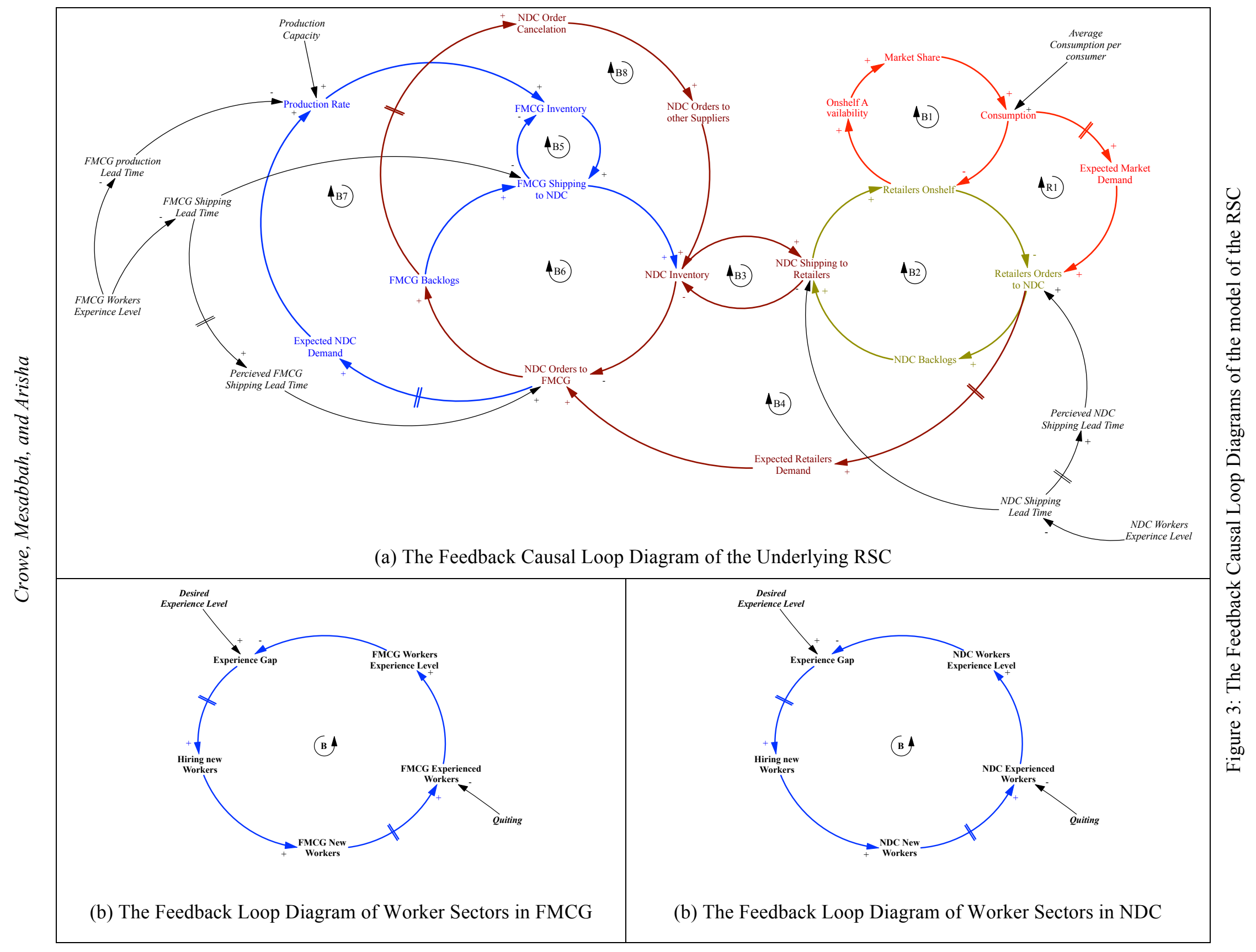


Crowe, Mesabbah, and Arisha

\subsubsection{Staff Turnover (Quitting Rate) FMCG}

According to IBEC (2013), there is on average a 7.5\% annual staff turnover rate in the wholesaler/grocery sector in Ireland. This is a close fit to FMCG's quit rate, but it seems to happen in clusters during the year. There are two drivers of these quitting clusters: Firstly, in certain departments within FMCG, there is an aging workforce who retire at the same time annually before the new financial year ends and they gain the most out of annual bonuses and pension lump sums. Secondly, as a large multi-national, FMCG is continuously reviewing its organizational structure to reduce costs and optimize efficiency. There is a trend of outsourcing roles and moving positions in-house to cheaper countries within FMCG. For example, moving the Irish Supply Chain planning function to FMCG in Poland.

The assumption for this scenario in the model will be based on the first driver, so that the model assumes that during the first two quarters of the model run one experienced worker quits every month from the FMCG. That will lead to a drop in the overall experience level within FMCG and consequently both production and delivery lead times will raise. This scenario is referred to as (S3).

\subsubsection{Staff Turnover (Quitting Rate) NDC}

Similar to the previous scenario, in this scenario it is assumed that during the first two quarters of the model run one experienced worker quits every month from the NDC. That will lead to a drop in the overall experience level within NDC and consequently delivery lead time will raise. S4 is used to refer to this scenario.

\subsubsection{Staff Turnover (Quitting Rate) FMCG and NDC}

This scenario combines the previous two scenarios (S3 and S4). It is assumed that during the first two quarters of the time period, one experienced worker quits every month from both FMCG and NDC. That will lead to a drop in the overall experience level within the FMCG and NDC and consequently production and delivery lead times will raise. S5 is used to refer to this scenario.

\section{SIMULATION ANALYSIS AND RESULTS}

The model is used to simulate the underlying RSC for one year. As mentioned previously, the system is initialized in a steady state, and all the scenarios take place after one month from the run start. The promotions scenario is included solely in S1 and in the other four scenarios in conjunction with other disruptions. Simulation results show the effect of promotions on consumption behavior. In all scenarios, one can see that consumption has raised during promotions period and then dropped for one month before it raises again to levels close the BAU's consumption (Figure 4.a). On the other side, the market share has dropped when the promotions become active (Figure 4.b). Loops B1 and R1 in Figure 3.a control dynamics of the market share, when consumption raised, B1 change the on-shelf level to a lower value and hence the market share. The feedback effect is supposed to reduce the consumption, but the exogenous impact of the average consumption per consumer influenced that reduction. Since B1 continued to bring down the market share until R1 becomes active, when the retailers started to adjust their daily order sizes in an attempt to absorb the rise in consumption. The shift in dominance (Sterman 2000) from B1 to R1 after approximately two weeks from the promotions will encourage the reinforcement growth of the market share by growth of the consumption until B1 retrieves the dominance back at the end of simulation and limits that growth back to BAU's market share (scenarios 4 and 5) or at a new stable point (scenarios 1 to 3 ). 
Crowe, Mesabbah, and Arisha

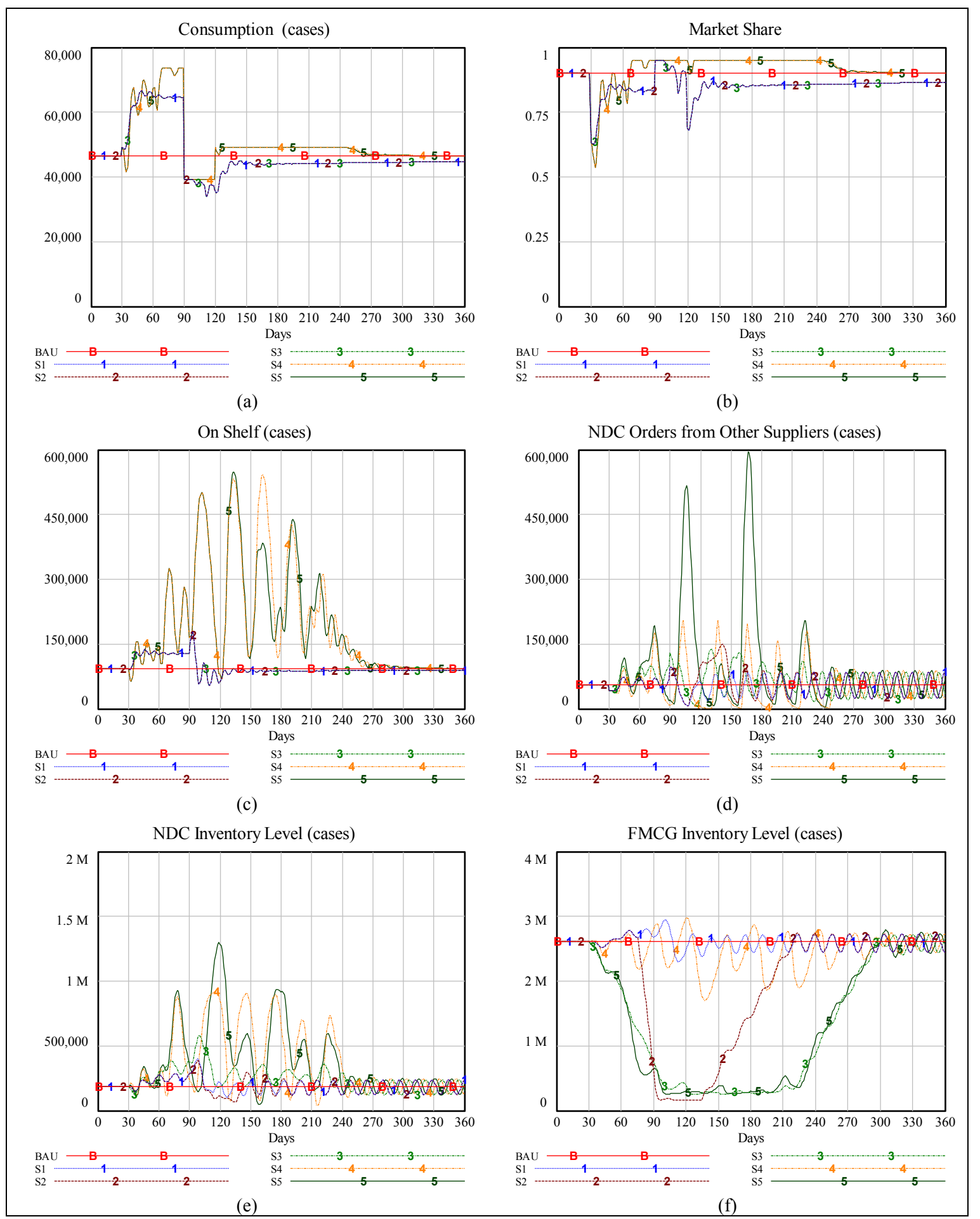

Figure 4: Simulation Results for Consumption, Market Share, Retailers On-shelf, NDC Orders from different Suppliers, and both NDC and FMCG Inventories. 


\section{Crowe, Mesabbah, and Arisha}

This tug of war between B1 and R1 is repeated during the simulation runs and has impacted the retailers on-shelf levels resulting in oscillatory behavior accompanied with high amplitudes in scenarios S4 and S5 (Figure 4.c). The reason for this significant difference in behavior from the market share's behavior, is that on-shelf level is involved with two other loops (B2 and B4) and both of them were incentivized by the NDC workers quit disruption introduced in S4 and S5 during the first two quarters of the simulation. It can be noticed that the behavior of the on-shelf level is almost the same in scenarios S1 to S3.This note indicates that disruptions introduced in S2 and S3 within FMCG echelon have no significant impact on the retailers echelon. This may be in contradiction with B4 (Figure 3.a) that has a holistic impact on the entire supply chain, so that any disruption at any part of the chain should affect the three echelons. The simulation results in Figure 4.d give justification to why that is not happening (i.e., no significant impact on retailers) when disruptions take place at the FMCG echelon. Actually, B8 (Figure 3.a) eases the effect of the disruption at the FMCG echelon on the retailers echelon. The growth in FMCG Backlogs, due to production disruption in $\mathrm{S} 2$ or workers quitting in S3, incentivized a higher rate of orders cancelation from NDC side due to the pressure of their Backlogs growth as well. As a substitution, NDC expedite orders from alternative suppliers, but with a $20 \%$ increase in the regular case price and this increase has an effect on their cash balance (Figure 5.a ).

Although all disruptions take place within the first quarter of the time period of simulation, it can be seen that resulted consequences effect continued to feature until the end of the third quarter in all scenarios, and they even get extended to the fourth quarter in some cases (S3 and S5 in Figure 4.f). As mentioned before, the embedded mechanism in the underlying RSC is driving the overall behavior of the RSC to a steady state point. The simulation results suggest, that the retailers echelon retrieves the equilibrium state in shorter time comparing to NDC and FMCG echelons (Figures 4.c to f). The inventory levels at the latter echelons have oscillatory behavior with almost fixed amplitudes and cycle times. However, this steady oscillatory behavior can be considered as a steady state for these echelons. Despite the longer impact of workers disruptions (S3 and S5) on the inventory level of FMCG (from month 1 to 10) comparing to the production disruption (S2) (from month 2 to 7), the production disruption has a higher impact on the decrease in cash balance (Figure 4 and 5.b). The results also demonstrate how the disruption at downstream echelons could impact the upstream echelon financially, such as S4, where the disruption takes place at the NDC workers sector has significant effect on the cash balance of FMCG.

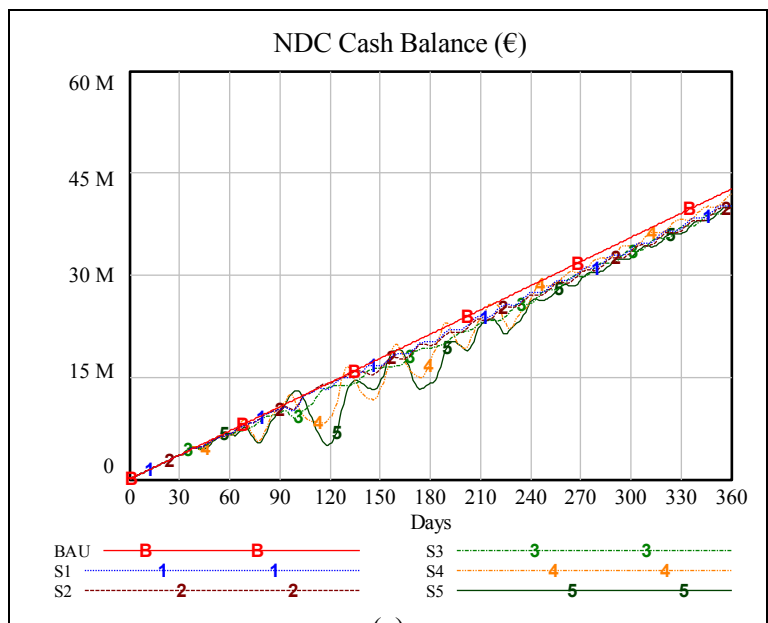

(a)

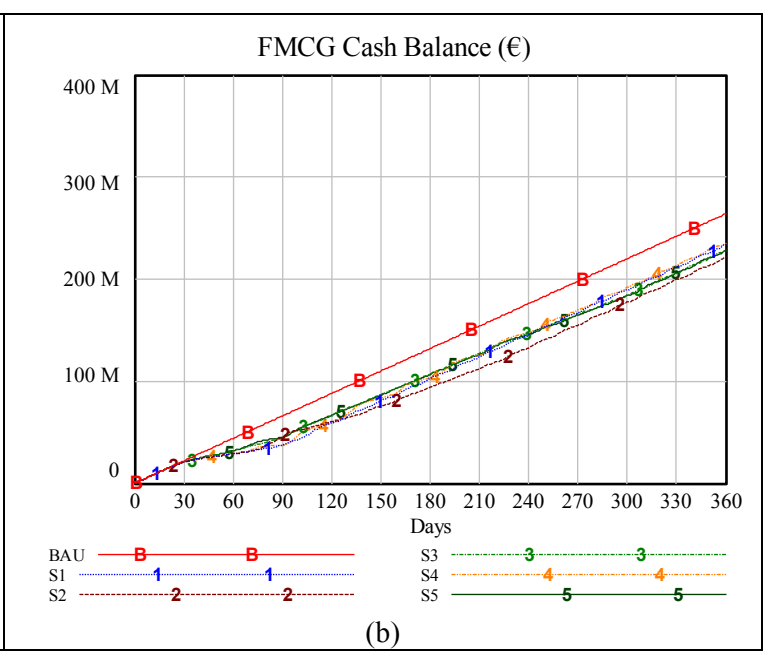

(b)

Figure 5: Simulation results for Cash Balance of NDC and FMCG. 
Crowe, Mesabbah, and Arisha

\section{CONCLUSIONS}

Successful RSC's are under pressures to compete in the volatile market by providing the right products to retail outlets in a timely manner all year long. High levels of demand uncertainty and promotion driven order patterns leaves RSC's vulnerable to disruption. Therefore there has been an increased emphasis put on accurate decision making and RSC system understanding. This has resulted in a need for models to support decisions to reduce costs while sustaining good customer service and profit margins.

An extended three Echelon RSC of a leading FMCG brand is studied in this paper, including the brand manufacturer (FMCG), distributor (NDC), and a national chain of Retailers. By increasing the scope of the paper to both up and downstream along the RSC, a more holistic understanding of order patterns and the consequences of disruptions can be achieved. By integrating the strategic performance management of the BSC with the dynamic, behavioral and feedback capabilities of SD, high level, accurate RSC decision making can be realized. Ultimately, the purpose is to provide decision makers with a model that can be used to understand unique behaviors, particularly the effect of disruptions on the RSC performance. A strategic decision to execute a high risk promotion while under 5 disruption scenarios based on BSC variables were run sequentially to fully understand the impact of this decision on key metrics along the RSC. Results show that there was less impact on retailer inventory levels and order patterns than with both NDC and FMCG. Moreover, the results demonstrate how the disruption at downstream echelons have significant impact on the upstream echelons financially. Future work in this model includes developing policy interventions that allow decision makers to test their decisions against these disruptions and understand how the system behavior will react.

\section{REFERENCES}

Bhagwat, R., and M. K. Sharma. 2007. "Performance Measurement of Supply Chain Management: A Balanced Scorecard Approach." Computers \& Industrial Engineering 53 (1):43-62.

Bia, B. 2012. Pathways for Growth - Review and Outlook May 2012. Accessed 17/08/2012. http://www.bordbia.ie/industryservices/information/publications/CorporatePublications/Documents/P athways for Growth - Review and Outlook May 2012.pdf.

Bia, B. 2013. Factsheet on the Irish Agriculture and Food \& Drink Sector. Accessed 16/12/2013. http://www.bordbia.ie/industryinfo/agri/pages/default.aspx.

Brewer, P. C., and T. W. Speh. 2001. Adapting The Balanced Scorecard To Supply Chain Management. Peerless Media, LLC.

Briano, E., C. Caballini, P. Giribone, and R. Revetria. 2010. "Using System Dynamics for Short Life Cycle Supply Chains Evaluation." In Proceedings of the 1994 Winter Simulation Conference, edited by B. Johansson, S. Jain, J. Montoya-Torres, J. Hugan, and E. Yücesan, 1820-1832. Piscataway, New Jersey: IEEE.

Fernie, J., and L. Sparks. 2009. Logistics and Retail Management: Emerging Issues and New Challenges in The Retail Supply Chain. London: Kogan Page.

Gonçalves, P., J. Hines, and J. D. Sterman. 2005. "The Impact of Endogenous Demand on Push-Pull Production Systems." System Dynamics Review 21 (3):187 - 216.

Hult, G. T. M., D. J. K. Jr, G. L. Adams, and J. A. Mena. 2008. "Supply Chain Orientation and Balanced Scorecard Performance." Journal of Managerial Issues 20 (4):526-544.

Kaplan, R. S., and D. P. Norton. 2001. The Strategy-Focused Organization: How Balanced Scorecard Companies Thrive in The New Business Environment. Boston: Harvard Business School Press.

Mahfouz, A., S. A. Hassan, and A. Arisha. 2010. "Practical Simulation Application: Evaluation of Process Control Parameters in Twisted-Pair Cables Manufacturing System." Simulation Modeling Practice and Theory 18 (5):471-482.

Parnell, G. S., P. J. Driscoll, and D. L. Henderson. 2011. Decision Making in Systems Engineering and Management. Vol. 81: John Wiley \& Sons.

Pidd, M. 2009. Tools for Thinking: Modeling in Management Science: No. 3rd. John Wiley and Sons Ltd. 
Rashwan, W., M. Ragab, W. Abo-Hamad, and A. Arisha. 2013. "Evaluating Policy Interventions for Delayed Discharge: A System Dynamics Approach." In Proceedings of the 1994 Winter Simulation Conference, edited by R. Pasupathy, S.-H. Kim, A. Tolk, R. Hill, and M. E. Kuhl, 2463-2474. Piscataway, New Jersey: IEEE.

Sterman, J. D. 2000. Business Dynamics: Systems Thinking and Modeling for a Complex World. Vol. 19: Irwin/McGraw-Hill Boston.

Supply Chain Council. 2013. SCOR 11 Web Overview. Last Modified 02/12/2011 Accessed 21/01/2013. http://supply-chain.org/f/SCOR11QRG.pdf.

Tobail, A., J. Crowe, and A. Arisha. 2011. "Learning by Gaming: Supply Chain Application." In Proceedings of the 1994 Winter Simulation Conference, edited by S. Jain, R.R. Creasey, J. Himmelspach, K.P. White, and M. Fu, 3935-3946. Piscataway, New Jersey: IEEE.

\section{AUTHOR BIOGRAPHIES}

JOHN CROWE, B.Sc. is a senior researcher at $3 \mathrm{~S}$ Group - College of Business, Dublin Institute of Technology (DIT). He joined the 3S group in 2009 with five years industry experience in logistics and inventory analysis. He received his B.Sc. degree specialized in Supply Chain Management from DIT with first class honors. John successfully won a national research scholarship from Irish Research Council for Science, Engineering and Technology (IRCSET). John has published several peer-reviewed articles in innovation in education and simulation and presented in international conferences. His research interests include supply chain management, simulation modeling application in business process analysis, system dynamics and simulation-based learning and education. His email address is <john.crowe@dit.ie>.

MOHAMMED MESABBAH, M.Sc. is a researcher in 3S Group (A research unit specialized in simulation and optimization of complex business processes) in College of Business - Dublin Institute of Technology (DIT)). He joined the 3S Group in 2013. He has a B.Sc. degree in Operations Research and decision support form Cairo University and M.Sc. in System Dynamics from University of Bergen. His research interests include Decision Support, Modeling and Simulation, Optimization, Computational intelligence and Game Theory. His email address is<mohamed.mesabbah@dit.ie>.

AMR ARISHA, Ph.D. is the Director of the $3 \mathrm{~S}$ Group and the Head of International Business Department at College of Business, Dublin Institute of Technology (DIT). He received his $\mathrm{PhD}$ in Industrial Engineering from Dublin City University (DCU). Intel-Ireland has sponsored his research from 2000 - 2005. His research path is focused on the ultimate goal of developing an integrated solution framework leveraging existing mathematical and systems tools from a number of fundamental approaches including system analysis, value stream mapping, stochastic modelling, game theory, simulation and optimization. His work places the quest for operations excellence at the heart of many contemporary challenges in applications such as healthcare, supply-chain management, production scheduling, and teaching/training. He is a member in IIE, IMECH, IEI, ESE, ORS, IEEE and ASME and Chief Examiner at MII. His e-mail address is<amr.arisha@dit.ie>. 